GENDER STEREOTYPES

A statement drawn about attitude and behaviors that are typically before making any normal and appropriate decisions for a person in a particular culture based on his or her biological sex.

A foundation created by community, society or by any one because of once gender, it may or may not affect an individual just because of their gender.

\section{GENDER STEREOTYPES AT WORKPLACE}

Gender stereotype is the most common practice which plays a vital role everywhere like; community, society, households, workplace etc. workplace is the place where gender stereotypes affects decisions taken at every level of organisation that is bias decisions may be taken because of once gender which may affect performance of an individual either positively or negatively.

Gender stereotypes itself is the main reason for creating such biasness at workplace, while there may be several reasons also because of which gender stereotypes take place at workplace, for instances; past experience, upbringing, etc.

\section{LEADERSHIP}

Leadership is an ability to set or/and achieve the goals at certain point of time, takes quick and effective decision, overshadow the competition and also inspire others to perform better.

\section{IMPACT OF GENDER STEREOTYPES ON LEADERSHIP AT WORKPLACE}

Gender stereotypes not only affect performance of individual but also it affects leadership quality of individual if biased decisions are taken at any level of organization.

Many researchers explore many facts in their study that gender segregation plays an important role at workplace. And at senior level women's are underrepresented even though they are at par or sometimes more intelligent and capable then men's, this results in losing talent, skills and ability present in the organization on the other hand many organizations provides different types of benefits to females workers as per their policies of organization but when it comes to leadership they give more preference to male workers.
GENDER AND ECONOMIC POLICY DISCUSSION FORUM GENDER EQUALITY IN WORKPLACE IN INDIA

The gender and economic policy (GEP) discussion forum on gender equality in workplace in India was held on $23^{\text {rd }}$ September 2015. The ultimate objective of the panel discussion was to create cross-sectoral to engagement to encourage gender equality at workplace in India, where a panel is a collaboration between Heinrich Boll stiftung, Institute of social studies trust and gender at work.

\section{Recent legislative changes and policy initiative}

Recently, the two laws have been enacted to encourage gender equality at workplace in India and they are as follows:

1. The companies act, 2013:

This act specifies that every publicly listed company has to appoint a women director on its board. Spenser Stuart India Board Index 2014 found that the women accounted for only 8 percent of directors on the Bombay stock exchange (BSE) 100 companies in 2012.

2. The sexual harassment of women at workplace (prevention, prohibition and rederessal) Act, 2013: Since, December 2013, the sexual harassment act is aimed to "provided protection against sexual harassment and for the prevention and redressal of complaints of sexual harassment". This act also expanded the definition of the workplace to cover different kinds of work.

\section{KEY CHALLENGES}

Despite India's admirable record of economic growth in the past two decades since liberalization, gender inequalities in the workplace persist. Gender inequality in the workplace manifests itself in multiple forms:

1. Gender gap in employment

2. Gender gap in management and leadership

3. Gender pay-gap

4. Uneven power relation

5. Sexual harassment

6. Care work

Although biases and stereotypes continue to persist within in India, the situation seems to be changing, a bit slowly. There is a increasing recognition of the need to advance gender equality within organization in India, but we are still a long way in understanding 
'why' women find it difficult to work in organizations and 'how' to advance gender equality in organization.

\section{OBJECTIVE}

$>$ To identify that, whether "glass ceiling" is created or not because of gender stereotypes.

$>$ To identify how gender stereotypes affect performance of employees and also decisions taken at every level of organization.

\section{LITERATURE REVIEW}

Menaha Shanmugam, R.D.G Amaratunga, R.P. Haigh in 2007, and Leadership Styles: Gender similarities, differences and perceptions, in which they analyze in their research paper that the contribution of leadership styles that are typically adopted by females in the context of construction industry. They mainly focus on how the leadership styles naturally adopted by women would help to address certain problems pertaining in the construction industry. They also tried to find out that apart from the traditional stereotypes whether women confront any other construction specific barriers to come to top leading positions. Their final study attempt to achieve a goal to give recommendations to increase the number of women leaders in construction.

Janka I. Stoker, Mandy Van der velde and Joris Lammers in $19^{\text {th }}$ march 2011 , Factors relating to managerial stereotypes: The role of gender of the employees and the manager and management gender ratio in which they concluded in their study that there are several ways to improve the positions of women in organizations while the wisest way is to use all simultaneously. They also admit that increasing the number of women in organisations is not only way to improve the image of female management. Their results also imply that only appointing women to higher positions will not be enough: having actual experience working for female manager leads employees to describe their ideal manager as hermaphrodite rather than masculine.

Dr. Arijit Sikdar and Dr. Sumit in June 2008, An Exploration of gender stereotypes in perception and practice of leadership in which they expected to throw light on how men and women in living society see gender-stereotyping of leadership. This would provide a better understanding of why a wall like the "glass ceiling" is always there for women while they plan for career and what they need to do to break such walls like "glass ceiling". They find out that while taking decisions for choosing leaders, being gender biased leads to the elimination of candidates who deserves more which causes loss to organization.

Crystal L. Hoyt in July 2010, Gender-based stereotypes in the workplace: The case of Greece in which they explores that how gender in leadership by focusing on the difficulties women experience in attaining and being seen as effective in top leadership position. She also examine that how stereotypes, prejudice and discrimination contribute to women's under-representation in elite leadership roles by both impacting perceptions of and responses to women as well as impacting the experiences of women themselves. At last she also concluded about the thoughts on promoting parity in top-level leadership.

Madeline E. Heilman and Alice H. Eagery in 2008, Gender stereotypes are alive, well and busy producing workplace discrimination in which they fails to influence the current theory of how gender stereotypes creates sex discrimination. They also claims that if they thoroughly reviewed the sex discrimination literature and properly paid attention to the scientific issues than the results would be no doubt have been more productive exchange views.

Vishal K. Gupta, Daniel B. Turban, Arzuwasti and Arijit Sikdar in 6 march 2009, the role of gender stereotypes in perceptions of entrepreneurs and intentions to become an entrepreneur provided a strong evidence that the gender characterization, in the form of gender-role stereotypes and gender identification all are related to the perceptions and intention to become an entrepreneur. In their study they all found that both young men and women have combine entrepreneurs with stereotypically masculine characteristics. From the data they collected and interpreted in their study indirectly speak about the views for entrepreneurship that indicates that women lack at certain characteristics, traits and skills that are needed to become entrepreneurs.

Jawad Syed and Memoona Tariq in 02 December 2016, had done a research study on Paradox of gender and leadership in India: a critical review of Mardaani in which their purpose of the study is to throw some light on the phases and dynamic nature of gender and leadership in India through a critical review of Indian film Mardaani, where the review shows that masculine stereotypes of leadership are 
simultaneously reinforced and shattered in the Indian context, and that despite all the odds, women's role in organisations is characterised by dynamism and change.

Arijit Sikdar and Sumit Matra in 2013, Genderrole stereotypes: Perception and practice of leadership in the middle east, in which their purpose is to investigate the emergence of women leaders in UAE organisation by going beyond biological sex role biases to identify leadership as masculine or feminine gendered role stereotypes in organizations. In which their findings indicates that within organisations in the UAE, employees feedback highlights gender-role stereotypes as defining leadership roles, rather than individual biological sex and their traditional family and social role. The findings reveal that in UAE, gender stereotypes influence leadership intentions and behaviour rather than individual biological sex and related traditions.

Kenneth S. Rhee and Tracey H. Sigler in April 2015, Untangling the relationship between gender and leadership, in which their purpose of the study is to empirically explore the perceptions of leader effectiveness and preference on gender and leadership style. The results showed that although subjects found participatory leaders to be more effective and also preferred such a style over authoritarian leaders, male leaders were rated to be more effective and more preferred over female leaders. Women leaders who against their gender stereotypes were perceived as even less effective and less preferred than male leaders who exhibited the same style that was identified as a more masculine style.

Dimitrios Mihail in July 2006 Gender-based stereotypes in the workplace: The case of Greece, their aim for the research on gender stereotypes would provide valuable information to corporate leaders. They design this study to explore the relationship between attitude towards women as managers and gender-based stereotypes. Their findings indicate that the primary source of shaping respondents attitudes is their own gender. Other personal characteristics such as age, education, managerial experience and working under a female supervisor seem not to have a measurable effect on employee's stereotypic attitudes towards women in management.

\section{RESEARCH GAP}

$>$ The research was based on primary collection of data; there may be chance of human error and bias.

$>$ The research was dependent on the information provided by the respondents who were very reluctant in providing right information and were careless.

$>$ As associated with every project, time and money were the major limitation with project.

$>$ Due to unwillingness of providing information, the respondents fill the questionnaire casually.

The projection is purely based on face to face meeting with respondents.

In this survey the major problem faced is the nonco-operative behavior of some of the respondents.

\section{RESEARCH METHODOLOGY}

\section{RESEARCH DESIGN:}

The research design adopted is descriptive and exploratory in nature as it is concerned with describing how gender stereotypes are created at workplace which affects leadership of an individual/ employee. Descriptive as well as exploratory research is used for the study as it relates to collection and survey of data from primary respondents followed by the analysis and interpretation and the secondary data from previous researches for the base of the study.

\section{DATA COLLECTION:}

The data is collected from both primary and secondary source according to the need of the research. Primary data is collected through a structured questionnaire and electronic media (like Google Docs). The questionnaire is prepared by keeping in mind the objectives of the research as it is very important that some of the objectives will be fulfilled through questionnaire.

On the other hand previous study also helps in fulfilling some of the objectives as it guides towards further study. Secondary data is easily obtainable than the primary research. As researchers had drawn conclusions at the end of the study which is already analysed and interpreted result.

In primary source, data is collected through observation, questionnaire, sample survey in random form and through data collection from different organisation of service sector. 


\section{SAMPLE DESIGN}

1. The sampling design followed here is nonprobability sampling. As they are deliberately selected concerned by the choice of items remains supreme.

2. Convenience sampling is also used as one of the probability sampling because it is accessible as per convenience and proximity.

\section{TOOLS FOR DATA ANALYSIS:}

\section{Reliability Test:}

This test is apply to check the reliability of the variables. Crone Bach's alpha in this test shows measure of internal consistency that is as a group how closely set of items are related. A high value for alpha does not imply that the measure is one dimensional. If cronbach's alpha value is more than 0.7 the data is said to be reliable and can undergo further analysis.

2. One way anova:

The one way analysis of variance is used to determine whether there are any statically significant difference

between the means of two or more independent groups.

\section{DATA INTERPRETATION}

1. Reliability Test

\section{Case Processing Summary}

\begin{tabular}{|l|l|l|l|l|}
\hline \multirow{3}{*}{ Cases } & & \multicolumn{1}{|c|}{ N } & \multicolumn{1}{c|}{$\%$} \\
\cline { 2 - 4 } & Valid $^{\text {Excluded }}$ & 249 & 4 & 98.4 \\
\cline { 2 - 4 } & Total $^{\text {a }}$ & 253 & 1.6 \\
\hline
\end{tabular}

a. Listwise deletion based on all variables in the procedure.

\section{Reliability Statistics}

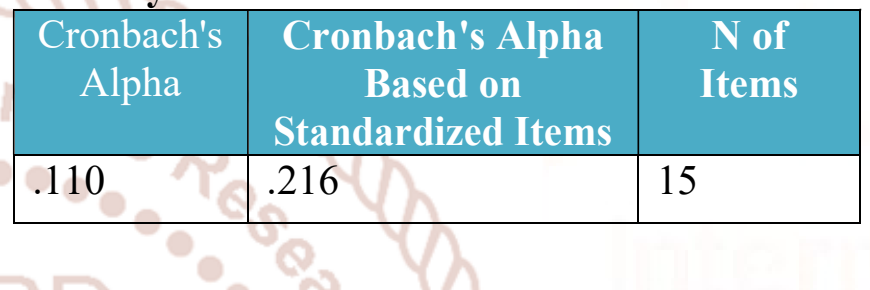

\section{Summary Item Statistics}

\begin{tabular}{|l|c|c|c|c|c|c|c|}
\hline & Mean & $\begin{array}{c}\text { Minim } \\
\text { um }\end{array}$ & $\begin{array}{c}\text { Maximu } \\
\text { m }\end{array}$ & Range & $\begin{array}{c}\text { Maximum / } \\
\text { Minimum }\end{array}$ & $\begin{array}{c}\text { Varian } \\
\text { ce }\end{array}$ & \multicolumn{1}{|c|}{$\begin{array}{c}\text { N of } \\
\text { Items }\end{array}$} \\
\hline $\begin{array}{l}\text { Item } \\
\text { Means }\end{array}$ & 2.520 & 1.341 & 3.7150 & 2.373 & 2.769 & .648 & 15 \\
\hline
\end{tabular}

The observed value shows that the value of crone Bach's alpha is 0.110 for 15 items taken in the present study, as the value is more than .7 hence it interpreted the research instrument is reliable to undergo further analysis.

All the 8 dependent variables are tested on the gender factor which is independent and it shows the following results:

1. In first variable, considering gender in favour of individuals' job the value of hypothesis is rejected because its value is more than level of significance that is 0.05 .

Null hypothesis is rejected and alternate hypothesis is not rejected here.

2. In second variable, encountering barriers on the way of individual's current position because of gender the value of hypothesis is rejected because its value is more than level of significance that is 0.05 .

Null hypothesis is rejected and alternate hypothesis is not rejected.
3. In third variable, Attitude of manger changes because of gender the value of hypothesis is rejected because its value is more than level of significance that is 0.05 .

Null hypothesis is rejected and alternate hypothesis is not rejected.

4. In fourth variable, male and female employees are on the same line regarding work dynamics, task, salary, time flexibility etc.

The value of hypothesis is rejected because its value is more than level of significance that is 0.05 .

Null hypothesis is rejected and alternate hypothesis is not rejected.

5. In fifth variable, colleagues are perceived in a similar way to those who are in opposite gender the value of hypothesis is not rejected because its value is less than level of significance that is 0.05 and the level of significance is 0.063 .

Null hypothesis is not rejected and alternate hypothesis is rejected. 
6. In sixth variable, treating fairly in the organisation the value of hypothesis is rejected because its value is more than level of significance that is 0.05 .

Null hypothesis is rejected and alternate hypothesis is not rejected here.

7. In seventh variable, assigning to a specific job role because of gender the value of hypothesis is not rejected because its value is less than level of significance that is 0.05 and the level of significance is 0.070 .

Null hypothesis is not rejected and alternate hypothesis is rejected.

8. In eighth variable, gender is overlapping capabilities while delegating authorities the value of hypothesis is rejected because its value is more than level of significance that is 0.05 .

Null hypothesis is rejected and alternate hypothesis is not rejected here.

All the 8 dependent variables are tested on the age factor which is independent and it shows the following results:

1. In first variable, considering gender in favour of individuals' job the value of hypothesis is not rejected because its value is less than level of significance that is 0.05 level of significance is 0.007 .

Null hypothesis is not rejected and alternate hypothesis is rejected here.

2. In second variable, encountering barriers on the way of individual's current position because of gender the value of hypothesis is not rejected because its value is less than level of significance that is 0.05 level of significance is 0.068 .

Null hypothesis is not rejected and alternate hypothesis is rejected here.

3. In third variable, Attitude of manger changes because of gender the value of hypothesis is not rejected because its value is less than level of significance that is 0.05 level of significance is 0.027 .

Null hypothesis is not rejected and alternate hypothesis is rejected here.

4. In fourth variable, male and female employees are on the same line regarding work dynamics, task, salary, time flexibility etc. the value of hypothesis is not rejected because its value is less than level of significance that is 0.05 level of significance is 0.087 .

Null hypothesis is not rejected and alternate hypothesis is rejected here.

5. In fifth variable, colleagues are perceived in a similar way to those who are in opposite gender The value of hypothesis is rejected because its value is more than level of significance that is 0.05 .

Null hypothesis is rejected and alternate hypothesis is not rejected.

6. In sixth variable, treating fairly in the organisation. The value of hypothesis is not rejected because its value is less than level of significance that is 0.05 level of significance is 0.000 .

Null hypothesis is not rejected and alternate hypothesis is rejected here.

7. In seventh variable, assigning to a specific job role because of gender the value of hypothesis is not rejected because its value is less than level of significance that is 0.05 and the level of significance is 0.000 .

Null hypothesis is not rejected and alternate hypothesis is rejected.

8. In eighth variable, gender is overlapping capabilities while delegating authorities the value of hypothesis is not rejected because its value is less than level of significance that is 0.05 and the level of significance is 0.000 .

Null hypothesis is not rejected and alternate hypothesis is rejected.

All the 8 dependent variables are tested on the marital status factor which is independent and it shows the following results:

1. In first variable, considering gender in favour of individuals' job the value of hypothesis is not rejected because its value is less than level of significance that is 0.05 level of significance is 0.081 .

Null hypothesis is not rejected and alternate hypothesis is rejected here.

2. In second variable, encountering barriers on the way of individual's current position because of gender the value of hypothesis is not rejected 
because its value is less than level of significance that is 0.05 level of significance is 0.001 .

Null hypothesis is not rejected and alternate hypothesis is rejected here.

3. In third variable, Attitude of manger changes because of gender the value of hypothesis is not rejected because its value is less than level of significance that is 0.05 level of significance is 0.003 .

Null hypothesis is not rejected and alternate hypothesis is rejected here.

4. In fourth variable, male and female employees are on the same line regarding work dynamics, task, salary, time flexibility etc. the value of hypothesis is not rejected because its value is less than level of significance that is 0.05 level of significance is 0.052 .

Null hypothesis is not rejected and alternate hypothesis is rejected here.

5. In fifth variable, colleagues are perceived in a similar way to those who are in opposite gender The value of hypothesis is rejected because its value is more than level of significance that is 0.05 .

Null hypothesis is rejected and alternate hypothesis is not rejected.

6. In sixth variable, treating fairly in the organisation. The value of hypothesis is not rejected because its value is less than level of significance that is 0.05 level of significance is 0.002 .

Null hypothesis is not rejected and alternate hypothesis is rejected here.

7. In seventh variable, assigning to a specific job role because of gender the value of hypothesis is not rejected because its value is less than level of significance that is 0.05 and the level of significance is 0.000 .

Null hypothesis is not rejected and alternate hypothesis is rejected.

8. In eighth variable, gender is overlapping capabilities while delegating authorities the value of hypothesis is rejected because its value is more than level of significance that is 0.05 and.

Null hypothesis is rejected and alternate hypothesis is not rejected.
All the 8 dependent variables are tested on the education qualification factor which is independent and it shows the following results:

1. In first variable, considering gender in favour of individuals' job the value of hypothesis is not rejected because its value is less than level of significance that is 0.05 level of significance is 0.011 .

Null hypothesis is not rejected and alternate hypothesis is rejected here.

2. In second variable, encountering barriers on the way of individual's current position because of gender the value of hypothesis is not rejected because its value is less than level of significance that is 0.05 level of significance is 0.000 .

Null hypothesis is not rejected and alternate hypothesis is rejected here.

3. In third variable, Attitude of manger changes because of gender the value of hypothesis is not rejected because its value is less than level of significance that is 0.05 level of significance is 0.000 .

Null hypothesis is not rejected and alternate hypothesis is rejected here.

4. In fourth variable, male and female employees are on the same line regarding work dynamics, task, salary, time flexibility etc. the value of hypothesis is rejected because its value is less than level of significance that is 0.05 .

Null hypothesis is rejected and alternate hypothesis is not rejected here.

5. In fifth variable, colleagues are perceived in a similar way to those who are in opposite gender The value of hypothesis is not rejected because its value is more than level of significance that is 0.05 the level of significance is 0.001 .

Null hypothesis is not rejected and alternate hypothesis is rejected.

6. In sixth variable, treating fairly in the organisation. The value of hypothesis is not rejected because its value is less than level of significance that is 0.05 level of significance is 0.000 .

Null hypothesis is not rejected and alternate hypothesis is rejected here. 
7. In seventh variable, assigning to a specific job role because of gender the value of hypothesis is not rejected because its value is less than level of significance that is 0.05 and the level of significance is 0.000 .

Null hypothesis is not rejected and alternate hypothesis is rejected.

8. In eighth variable, gender is overlapping capabilities while delegating authorities the value of hypothesis is not rejected because its value is more than level of significance that is 0.05 and the level of significance is 0.037 .

Null hypothesis is not rejected and alternate hypothesis is rejected.

All the 8 dependent variables are tested on the income per annum factor which is independent and it shows the following results:

1. In first variable, considering gender in favour of individuals' job the value of hypothesis is not rejected because its value is less than level of significance that is 0.05 level of significance is 0.001 .

Null hypothesis is not rejected and alternate hypothesis is rejected here.

2. In second variable, encountering barriers on the way of individual's current position because of gender the value of hypothesis is not rejected because its value is less than level of significance that is 0.05 level of significance is 0.000 .

Null hypothesis is not rejected and alternate hypothesis is rejected here.

3. In third variable, Attitude of manger changes because of gender the value of hypothesis is rejected because its value is less than level of significance that is 0.05 .

Null hypothesis is rejected and alternate hypothesis is not rejected here.

4. In fourth variable, male and female employees are on the same line regarding work dynamics, task, salary, time flexibility etc. the value of hypothesis is rejected because its value is less than level of significance that is 0.000 .

Null hypothesis is rejected and alternate hypothesis is not rejected here.
5. In fifth variable, colleagues are perceived in a similar way to those who are in opposite gender The value of hypothesis is not rejected because its value is more than level of significance that is 0.05 the level of significance is 0.063 .

Null hypothesis is not rejected and alternate hypothesis is rejected.

6. In sixth variable, treating fairly in the organisation. The value of hypothesis is not rejected because its value is less than level of significance that is 0.05 level of significance is 0.000 .

Null hypothesis is not rejected and alternate hypothesis is rejected here.

7. In seventh variable, assigning to a specific job role because of gender the value of hypothesis is not rejected because its value is less than level of significance that is 0.05 and the level of significance is 0.000 .

Null hypothesis is not rejected and alternate hypothesis is rejected.

8. In eighth variable, gender is overlapping capabilities while delegating authorities the value of hypothesis is not rejected because its value is more than level of significance that is 0.05 and the level of significance is 0.000 .

Null hypothesis is not rejected and alternate hypothesis is rejected.

All the 8 dependent variables are tested on the level of position factor which is independent and it shows the following results:

1. In first variable, considering gender in favour of individuals' job the value of hypothesis is not rejected because its value is less than level of significance that is 0.05 level of significance is 0.000 .

Null hypothesis is not rejected and alternate hypothesis is rejected here.

2. In second variable, encountering barriers on the way of individual's current position because of gender the value of hypothesis is not rejected because its value is less than level of significance that is 0.05 level of significance is 0.063 .

Null hypothesis is not rejected and alternate hypothesis is rejected here. 
3. In third variable, Attitude of manger changes because of gender the value of hypothesis is not rejected because its value is less than level of significance that is 0.05 the level of significance is 0.31 .

Null hypothesis is not rejected and alternate hypothesis is rejected here.

4. In fourth variable, male and female employees are on the same line regarding work dynamics, task, salary, time flexibility etc. the value of hypothesis is rejected because its value is less than level of significance that is 0.000 .

Null hypothesis is rejected and alternate hypothesis is not rejected here.

5. In fifth variable, colleagues are perceived in a similar way to those who are in opposite gender The value of hypothesis is not rejected because its value is more than level of significance that is 0.05 the level of significance is 0.000 .

Null hypothesis is not rejected and alternate hypothesis is rejected.

6. In sixth variable, treating fairly in the organisation. The value of hypothesis is not rejected because its value is less than level of significance that is 0.05 level of significance is 0.000 .

Null hypothesis is not rejected and alternate hypothesis is rejected here.

7. In seventh variable, assigning to a specific job role because of gender the value of hypothesis is not rejected because its value is less than level of significance that is 0.05 and the level of significance is 0.000 .

Null hypothesis is not rejected and alternate hypothesis is rejected.

8. In eighth variable, gender is overlapping capabilities while delegating authorities the value of hypothesis is not rejected because its value is more than level of significance that is 0.05 and the level of significance is 0.003 .

Null hypothesis is not rejected and alternate hypothesis is rejected.

All the 8 dependent variables are tested on the working hours factor which is independent and it shows the following results:
1. In first variable, considering gender in favour of individuals' job the value of hypothesis is not rejected because its value is less than level of significance that is 0.05 level of significance is 0.000 .

Null hypothesis is not rejected and alternate hypothesis is rejected here.

2. In second variable, encountering barriers on the way of individual's current position because of gender the value of hypothesis is not rejected because its value is less than level of significance that is 0.05 level of significance is 0.000 .

Null hypothesis is not rejected and alternate hypothesis is rejected here.

3. In third variable, Attitude of manger changes because of gender the value of hypothesis is not rejected because its value is less than level of significance that is 0.05 the level of significance is 0.007 .

Null hypothesis is not rejected and alternate hypothesis is rejected here.

4. In fourth variable, male and female employees are on the same line regarding work dynamics, task, salary, time flexibility etc. the value of hypothesis is rejected because its value is less than level of significance that is 0.000 .

Null hypothesis is rejected and alternate hypothesis is not rejected here.

5. In fifth variable, colleagues are perceived in a similar way to those who are in opposite gender The value of hypothesis is not rejected because its value is more than level of significance that is 0.05 the level of significance is 0.000 .

Null hypothesis is not rejected and alternate hypothesis is rejected.

6. In sixth variable, treating fairly in the organisation. The value of hypothesis is not rejected because its value is less than level of significance that is 0.05 level of significance is 0.000 .

Null hypothesis is not rejected and alternate hypothesis is rejected here.

7. In seventh variable, assigning to a specific job role because of gender the value of hypothesis is not rejected because its value is less than level of 
significance that is 0.05 and the level of how many opportunities and/or barriers created at significance is 0.000 . different level of organisation of service sector.

Null hypothesis is not rejected and alternate hypothesis is rejected.

8. In eighth variable, gender is overlapping capabilities while delegating authorities the value of hypothesis is rejected because its value is more than level of significance that is 0.05 .

Null hypothesis is rejected

\section{CONCLUSION}

The purpose of the study is to determine how gender stereotypes affect workplace or working culture or environment in service sector in Indore, where several studies were conducted before on gender stereotypes earlier in which they mainly focuses on how gender stereotypes affect performance of women or female employees while gender stereotype is a concept define foundations created for individuals because of once gender which may or may not affect individuals either positively or negatively.

In this research study there are several aspects covered which shows how gender stereotypes affect workplace for both male and female employees and

At last gender stereotypes may vary from organisation to organisation because it is not necessary that it will create a barrier in every organisation, according to the data it does not show any negative affect on any employees both male and female that they are facing any problem because of gender stereotypes.

While according to the secondary data collected from earlier research it shows that gender stereotypes affect female employees and for their welfare some policies were made by organisation as per the guidelines given by government.

\section{LIMITATIONS}

$>$ Time period is a limitation as the research had to be completed in just a period of few busy months.

The sample size of the research is however 250 but many time the intellects of the respondents were of the same level, which later showed that their responses were mostly similar.

Most of the respondents were giving biased responses as they are not interested in giving response to any type of surveys because of safety and security concern.

Limited availability of funds is also one of the barrier.

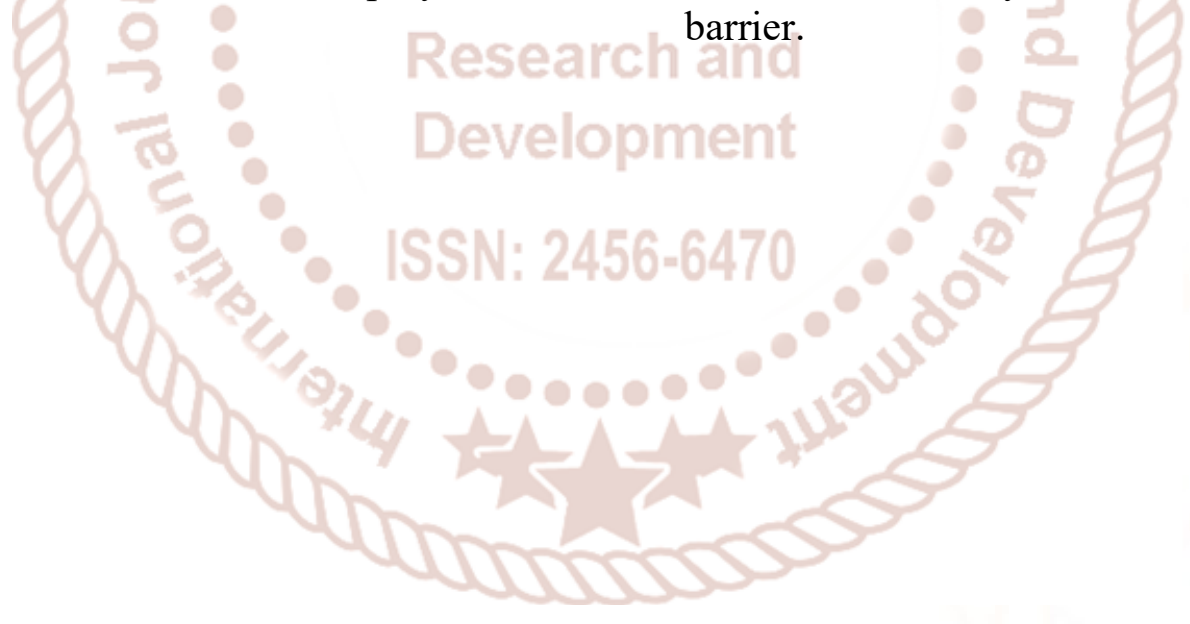

